\title{
Pengaruh Rekrutmen, Pelatihan, dan Konseling terhadap Produktivitas Kerja Karyawan pada PT. Telkom Akses Medan
}

\author{
Muhammad Nizam Suheil Siregar ${ }^{1}$, Pesta Ria Andriyani², Gregorius Bhima Rhessy Wellan ${ }^{3}$, \\ Sartika Limbong ${ }^{4}$, M. Agung Anggoro ${ }^{5}$ \\ 1,2,3,4,5 Universitas Prima Indonesia, jl Sekip, Petisah Tengah, Kota Medan \\ Correspondence email: mnizamsrg20@gmail.com
}

\begin{abstract}
Abstrak. Penelitian ini bertujuan untuk mengetahui Pengaruh Pengaruh Rekrutmen, Pelatihan dan Konseling terhadap Produktivitas Kerja Karyawan pada PT. Telkom Akses Medan baik sebagian maupun simultan. Metode penelitian menggunakan analisis deskriftif kuantitatif. Populasi dalam penelitian ini adalah seluruh karyawan di PT. Telkom Akses Medan yang berjumlah sebanyak 462 orang. Teknik analisis data menggunakan Uji F, Uji T, dan Regresi Linier Berganda dan analisis data menggunakan SPSS versi 20. Berdasarkan hasil analisis data dalam penelitian ini menunjukan bahwa secara parsial dapat dilihat bahwa Variabel rekrutmen (X1) memiliki thitung sebesar 0,837 dan nilai ttabel sebesar 1,663 maka nilai thitung $<$ ttabel $(0,837<1,663)$ dan nilai sig. $0.00<0,405$. Hal ini berarti hipotesis ditolak yaitu : rekrutmen secara parsial tidak berpengaruh positif dan signifikan terhadap Produktivitas karyawan pada PT Telkom Akses Medan. Hasil penelitian menunjukan bahwa pelatihan ( $\left.\mathrm{X}_{2}\right)$ memiliki thitung sebesar 3,254 dan nilai ttabel sebesar 1,663 ma ka nilai thitung >ttabel $(3,254>1,663)$ dan nilai sig. $0.00<0,002$. Hal ini berarti hipotesis diterima yaitu : pelatihan berpengaruh positif dan signifikan terhadap produktivitas karyawan p ada PT Telkom Akses Medan. Hasil penelitian menunjukan bahwa konseling (X3) memiliki thitung sebesar 2,974 dan nilai ttabel sebesar 1,663 maka nilai thitung >ttabe $1(2,974>1,663)$ dan nilai sig. $0.00<0,004$. Hal ini berarti hipotesis diterima yaitu : konseling berpengaruh positif dan signifikan terhadap produktivitas karyawan pada PT Telkom Akses Medan.
\end{abstract}

Kata kunci: Konseling; Rekrutmen; Pelatihan; Produktivitas

Abstract. This study aims to determine the effect of the influence of Recruitment, Training and Counseling on Employee Productivity at PT. Telkom Medan access both partially and simultaneously. The research method uses quantitative descriptive analysis. The population in this study were all totaling 462 people. Data analysis techniques using the F Test, T Test, and Multiple Linear Regression. Based on the results of data analysis in this study shows that partially it can be seen that the recruitment variable (X1) has a tcount of 0.837 and a value of 1.663 , then the tcount value <ttable $(0.837<1.663)$ and a sig.0.00 value $<0.405$. This means the hypothesis is rejected namely: partial recruitment has no positive and significant effect on employee productivity at PT Telkom Akses Medan. The results showed that the training (X2) had a tcount of 3.254 and a t-table value of 1.663 , then a tcount $>$ ttable $(3.254>1.663)$ and a sig value. $0.00<0.002$. This means that the hypothesis is accepted: training has a positive and significant effect on employee productivity in PT Telkom Akses Medan. The results showed that counseling (X3) had a tcount of 2.974 and a t-table value of 1.663 then the tcount $>$ ttabe $l(2.974>1.663)$ and a sig value. $0.00<0.004$. This means that the hypothesis is accepted: counseling has a positive and significant effect on employee productivity at PT Telkom Akses Medan.

Keywords: Counseling; Productivity; Recruitment; Training

\section{PENDAHULUAN}

Produktivitas kerja merupakan suatu aspek paling penting dalam keberhasilan suatu perusahaan. Produktivitas merupakan ukuran yang ditentukan untuk mengetahui seberapa baik kualitas sumber daya manusia yang dimiliki serta dimanfaatkan guna mendapatkan hasil yang optimal. Maka dengan demikian agar produktivitas kerja karyawan maupun perusahaan tetap stabil pihak manajemen perusahaan perlu mempertimbangkan beberapa faktor yang menunjang peningkatan produktivitas secara menyeluruh.

Menurut Sutrisno (2016), Rekrutmen merupakan suatu proses mencari, mengadakan, menemukan, dan menarik para pelamar untuk dipekerjakan dalam suatu organisasi. Menurut Sutrisno (2017) dalam jurnal Nursyaidah Fitriani (2018), menyatakan bahwa sebuah proses rekrutmen yang dimulai dari pencarian calon dan berakhir sampai lamaran mereka diterima. Dimana salon yang diterima ialah yang memenuhi syarat untuk mengisi lowongan. Dimana keberhasilan rekrutmen ini akan membawa peningkatan produktivitas karyawan maupun perusahaan.

Diduga Rekrutmen berpengaruh terhadap peningkatan produktivitas kerja karyawan pada perusahaan. Rekrutmen berperan penting dalam proses memilih serta penempatan karyawan sesuai dengan kompetensi yang dimiliki setiap karyawan. Proses rekrutmen calon karyawan harus dilakukan secara tepat dan baik, jika proses ini berjalan sesuai prosedur yang ada akan menghasilkan sekelompok pelamar yang berkualitas dimana nantinya dapat menjamin dan memenuhi persyaratan yang berguna untuk organisasi perusahaan. 
Menurut Kasmir (2018) menyatakan bahwa pelatihan merupakan proses untuk membentuk dan membekali karyawan dengan menambah keahlian, kemampuan, pengetahuan dan perilakunya. Ichwan Aziz Sambodo (2016) menyatakan bahwa dengan adanya pelaksanaan program pelatihan dapat membentuk dan meningkatkan kemampuan dan pengetahuan karyawan, sehingga diharapkan dengan semakin sering program pelatihan dilaksanakan maka semakin tinggi pula tingkat produktivitasnya.

Dalam melaksanakan pekerjaan, karyawan tidak lepas dari pelatihan yang sudah ditetapkan oleh perusahaan. Diduga pelatihan berpengaruh dalam menciptakan produktivitas yang tinggi. Karena bagi seluruh calon karyawan baru agar siap untuk ditempatkan dibidang pekerjaan tertentu, perlu terlebih dulu untuk mengikuti pelatihan. Dalam arti karyawan siap untuk bekerja dan mau untuk mematuhi segala aturan yang telah ditetapkan oleh perusahaan, pelatihan ini bertujuan untuk melatih dan mengasah kemampuan karyawan, meningkatkan keterampilan, dan meningkatkan rasa bertanggung jawab akan pekerjaan dimana adanya pelatihan ini untuk meminimalisir kesalahan dalam bekerja.

Menurut Wibowo (2011), konseling merupakan aktivitas yang terjadi ditempat pekerjaan dimana seorang individu memikul tanggung jawab dan mengelola pengambilan keputusannya sendiri baik yang bersifat ada hubungannya dengan pekerjaan atau bersifat pribadi.

Dalam jurnal Suwarjo (2012), menyatakan bahwa karyawan merupakan salah satu komponen utama dalam perusahaan, maka kualitas dan kesejahteraan karyawan dalam perusahaan sangat menentukan kemajuan dan produktivitas karyawan maupun perusahaan, maka salah satu layanan yang perlu diberikan perusahaan kepada karyawan dalam rangka meningkatkan produktivitas dan kesejahteraan mereka ialah melalui layanan konseling.

Konseling berperan penting dalam meningkatnya atau menurunnya produktivitas kerja karyawan. Karena konseling berfungsi sebagai langkah menolong karyawan untuk mengatasi tekanan yang dialami dalam pekerjaan, biasanya konseling sangat dibutuhkan oleh karyawan baru yang susah untuk beradaptasi dengan lingkungan pekerjaan dan perusahaan, ada pula faktor lainnya ialah kesehatan fisik, psikologis seperti rasa cemas yang berlebihan terhadap pekerjaan, serta pola makan dan tidur yang kurang teratur karena sering mengerjakan tugas hingga larut malam. Keadaan tersebut berdampak pada kualitas kerja karyawan tersebut. Maka dari itu konseling menjadi sangat penting diadakan dalam suatu organisasi agar tidak menghambat produktivitas kerja perusahaan.

Menurut Sutrisno (2016), menyatakan bahwa produktivitas adalah perbandingan antara hasil yang dicapai dengan peran tenaga kerja persatuan waktu. Peran serta tenaga kerja disini adalah penggunaan sumber daya yang efesien dan efektif.
PT Telkom Akses merupakan salah satu anak perusahaan PT. Telekomunikasi Indonesia,Tbk yang sahamnya sepenuhnnya dimiliki oleh Telkom. Perusahaan ini bergerak di bidang konstruksi pembangunan dan manage service infrastruktur jaringan. PT Telkom Akses didirikan pada tanggal 12 Desember 2012. Diketahui pada tahun 2019 PT Telkom Akses Medan mengalami peningkatan sebesar 111.11\% dalam mecapai target pemasangan baru, diketahui target tahunan sebesar 50.795 pemasangan kabel baru, dan mampu dicapai perusahaan sebesar 56.439 pemasangan. Pencapaian target ini diduga kerena tingginya produktivitas kerja yang dimiliki oleh karyawan PT. Telkom Akses Medan.

\section{METODE \\ Tempat Penelitian}

Penelitian ini dilakukan pada PT Telkom Akses Witel Medan jln. Gaharu no.1 Kecamatan Medan Timur, Sumatera Utara 20236.

\section{Jenis Penelitian}

Pendekatan kuantitatif digunakan dalam pendekatan penelitian ini Menurut Sugiyono (2017) pendekatan kuantitatf ialah suatu jenis penelitian yang di landaskan terhadap filsafat positive yang di pergunakan untuk melaksanakan penelitian berkenan dengan sampel dan juga populasi tertentu.

\section{Populasi dan Sampel}

Adapun populasiyang di dapat dri penelitian ini adalah seluruh karyawan pada PT Telkom Akses Witel Medan berjumlah 462 responden, sampel di ambil secara acak, tanpa memeperhatikan tingkat yang ada tiap populasi, memiliki peluang yang sama dan diketahui untuk terpilihnya subjek, jumlah sampel di tentkan dengan rumus slovin sebanyak 82 responden, pengumpulan data dengan cara wawancara, kuisioner dan dokumen.

\section{Teknik Pengumpulan Data}

Pengolahan data dengan uji validitas dan realibilitas yang bertujuan untuk mengetahui suatu koesiner valid atau tidak, uji asumsi klasik serta analisis regresi berganda.

Kemampuan Model dalam menerangkan variasi Variabel dependen diukur dengan Koefisien Determinasi $\left(\mathrm{R}^{2}\right)$. Koefisien determinasi memiliki nilai antara nol dan satu. Walaupun nilai Adjusted $R^{2}$ di kehendaki bernilai positif, namun bisa saja nilai $A d j u s t e d R^{2}$ dapat benilai positif, uji $t$ dan uji $F$.

\section{HASIL DAN PEMBAHASAN Stastistik Deskriptif}


Muhammad Nizam Suheil Siregar et al, Pengaruh Rekrutmen, Pelatihan, dan Konseling terhadap Produktivitas Kerja Karyawan pada PT. Telkom Akses Medan

Tabel 1. Stastistik Deskriptif

\begin{tabular}{|c|c|c|c|c|c|}
\hline & N & Minimum & Maximum & Mean & $\begin{array}{c}\text { Std. } \\
\text { Deviation }\end{array}$ \\
\hline REKRUTMEN & 82 & 11 & 25 & 17.84 & 3.172 \\
PELATIHAN & 82 & 21 & 40 & 29.70 & 4.586 \\
KONSELING & 82 & 10 & 25 & 17.95 & 2.918 \\
PRODUKTIVITAS & 82 & 22 & 38 & 29.71 & 3.707 \\
Valid N (listwise) & 82 & & & & \\
\hline
\end{tabular}

Uji Asumsi Klasik

\section{Uji Normalitas Histrogram}

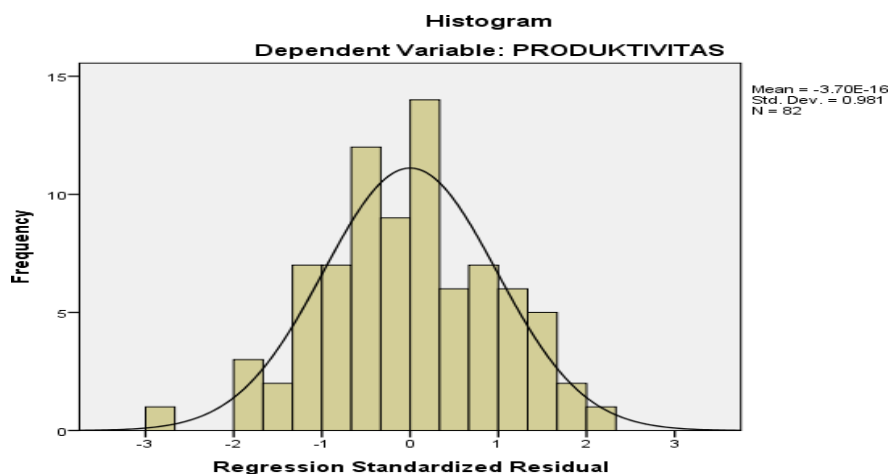

Gambar 1. Uji Normalitas Histrogram

Berdasarkan Gambar 1 terlihat bahwa grafik histrogram menunjukkan berdistribusi normal, hal ini dapat dilihat darikurva yang berbentuk seperti lonceng terbalik.

\section{Uji Normalitas Probability Plot}

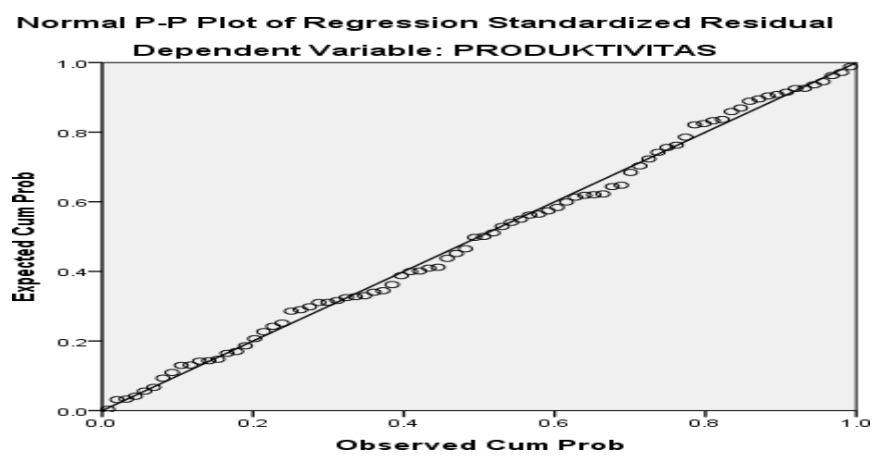

Gambar 2. Normalitas Probability plot

Berdasarkan Gambar 2 diatas menunjukan titik yang menyebar disekitar diagonal dan penyebaran yang mengikuti arah garis diagonal sehingga dapat disimpulkan bahwa data modal regresi berdistribusi normal.

Tabel 2. Uji Multikolineritas

\begin{tabular}{|l|r|r|}
\hline \multirow{2}{*}{ Model } & \multicolumn{3}{|c|}{ Collinearity Statistics } \\
\cline { 2 - 3 } & Tolerance & \multicolumn{1}{|c|}{ VIF } \\
\hline (Constant) & & \\
REKRUTMEN & .826 & 1.210 \\
PELATIHAN & .725 & 1.379 \\
KONSELING & .858 & 1.165 \\
\hline
\end{tabular}

Tabel 2 diatas menunjukan bahwa nilai tolerance tiap variabel independen sebagai Rekrutmen (X1) sebesar 0,826, Pelatihan (X2) sebesar 0,725 dan Konseling (X3) sebesar 0,858 lebih besar dari 0,1 sedangkan nilai VIF tiap variabel independen Rekrutmen (X1) sebesar 1,210, Pelatihan (X2) sebesar 1,379 dan Konseling (X3) sebesar 1,165 lebih kecil dari 10, maka data tersebut terbebas dari multikolinearitas.

\section{Koefisien Determinasi Hipotesis}

Adjusted $R$ Square dengan $\mathrm{R}^{2}$ merupakan nilai koefisien determinasi terkoreksi yang menyesuaikan $\mathrm{R}^{2}$ dengan cara membagi tiap sum of square dengan derajat bebas masing-masing.

Tabel 3. Model Summary

\begin{tabular}{|l|r|r|r|r|}
\hline Model & R & R Square & $\begin{array}{c}\text { Adjusted R } \\
\text { Square }\end{array}$ & $\begin{array}{c}\text { Std. Error of the } \\
\text { Estimate }\end{array}$ \\
\hline 1 & $.576^{\mathrm{a}}$ & .332 & .306 & 3.087 \\
\hline
\end{tabular}

Berdasarkan tabel 3 diatas bahwa dapat disimpulkan:

a. $\mathrm{R}=0.576$ berarti hubungan (corelation) antara variable rekrutmen, pelatihan dan konseling terhadap variable produktivitas tinggi.

b. Nilai Koefisien determinasi (R Square) adalah sebesar 0.332 , hal ini menunjukan bahwa 33,02\% variasi variable produktivitas (Y) dapat dijelaskan oleh variable rekrutmen (X1), pelatihan (X2) dan variable konseling (X3) sedangkan sisanya $66,98 \%$ adalah variable bebas lainnya yang tidak di jelaskan dalam penelitian ini.

\section{Pengujian Hipotesis Secara Simultan (Uji F)}

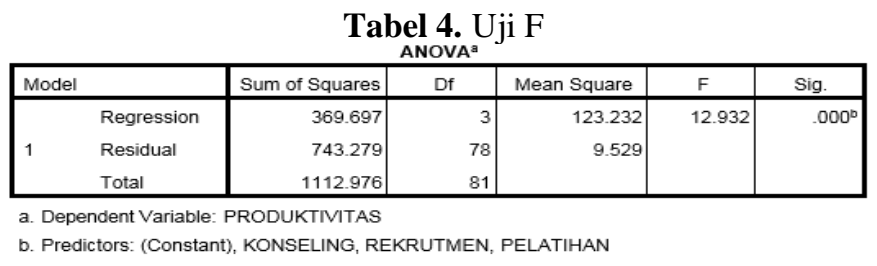

Berdasarkan Tabel 4 diatas, derajat bebas $1(\mathrm{df} 1)=$ $\mathrm{k}-1=4-1=3$, dan derajat bebas $2(\mathrm{df} 2)=\mathrm{n}-\mathrm{k}=82-4=78$, dimana $n=$ jumlah sampel, $\mathrm{k}=$ jumlah variabel, maka nilai Ftabel pada taraf kepercayaan signifikansi 0,05 adalah 2,72. Hasil pengujian hipotesis diperoleh nilai Fhitung sebesar 12,932 lebih besar dari Ftabel sebesar 2.72 dengan sig. $0.000<0.000$ maka hal ini menunjukkan bahwa H0 ditolak dan Ha diterima. Dengan demikian rekrutmen (X1), pelatihan (X2), dan konseling (X3) secara simultan (bersama-sama) berpengaruh positif dan signifikan terhadap variable produktivitas $(\mathrm{Y})$. 


\section{Pengujian Hipotesis Secara Simultan (Uji T)}

Tabel 5. Tabel T Coefficients $^{2}$

\begin{tabular}{|c|c|c|c|c|c|c|}
\hline \multicolumn{7}{|c|}{ Coefficients $^{\mathrm{a}}$} \\
\hline & \multirow[t]{2}{*}{ Model } & \multicolumn{2}{|c|}{ Unstandardized Coefficients } & \multirow{2}{*}{$\begin{array}{c}\text { Standardized } \\
\text { Coefficients } \\
\text { Beta } \\
\end{array}$} & \multirow[t]{2}{*}{$t$} & \multirow[t]{2}{*}{ Sig. } \\
\hline & & B & Std. Error & & & \\
\hline \multirow{4}{*}{1} & (Constant) & 12.668 & 2.863 & & 4.425 & .000 \\
\hline & REKRUTMEN & .100 & .119 & .085 & .837 & .405 \\
\hline & PELATIHAN & .286 & .088 & .354 & 3.254 & .002 \\
\hline & KONSELING & .377 & .127 & 297 & 2.974 & .004 \\
\hline
\end{tabular}

Berdasarkan Tabel 5 diatas menunjukkan bahwa:

1. Variabel rekrutmen (X1) memiliki thitung sebesar 0,837 dan nilai ttabel sebesar 1,663 maka nilai thitung <ttabel $\quad(0,837<1,663) \quad$ dan nilai sig.0.00<0,405. Hal ini berarti hipotesis ditolak yaitu : rekrutmen secara parsial tidak berpengaruh positif dan signifikan terhadap $\mathrm{p}$ roduktivitas karyawan pada PT Telkom Akses Medan.

2. Variabel pelatihan $\left(\mathrm{X}_{2}\right)$ memiliki thitung sebesar 3,254 dan nilai ttabel sebesar 1,663 ma ka nilai thitung $>$ ttabel $(3,254>1,663)$ dan nilai sig. $0.00<0,002$. Hal ini berarti hipotesis diterima yaitu : pelatihan berpengaruh positif dan signifikan terhadap produktivitas karyawan $\mathrm{p}$ ada PT Telkom Akses Medan.

3. Variabel konseling (X3) memiliki thitung sebesar 2,974 dan nilai ttabel sebesar 1,663 maka nilai thitung $>$ ttabel $(2,974>1,663)$ dan nilai sig. $0.00<0,004$. Hal ini berarti hipotesis diterima yaitu : konseling berpengaruh positif dan signifikan terhadap produktivitas karyawan $\mathrm{p}$ ada PT Telkom Akses Medan.

\section{Pembahasan}

\section{Pengaruh Rekrutmen terhadap Produktivitas}

Hasil perhitungan pengujian hipotesis secara parsial memiliki thitung sebesar 0,837 dan nilai tabel sebesar 1,663 maka nilai thitung <ttabel $(0,837<1,663)$ dan nilai sig. $0.00<0,405$. Hal ini berarti hipotesis ditolak yaitu : rekrutmen secara parsial tidak berpengaruh positif dan signifikan terhadap produktivitas karyawan pada PT Telkom Medan.

Hasil penelitian ini didukung oleh penelitian Tulus Siska Tjut Nya Din dan Jacky S.B Sumarauw (2018) bahwa tidak terdapat pengaruh antara proses rekrutmen dengan penurunan atau peningkatan produktivitas.

Berdasarkan hasil perbandingan diatas, maka dapat disimpulkan bahwa rekrutmen tidak selalu berpengaruh secara positif dan signifikan terhadap kinerja produktivitas kerja karyawan. Ada baiknya pihak perusahaan tidak hanya fokus pada sistem rekrutmen saja, melainkan fokus juga pada faktor-faktor lainnya yang lebih berpengaruh terhadap peningkatan produktivitas kerja karyawan maupun perusahaan.

\section{Pengaruh Pelatihan Terhadap Produktivitas}

Hasil perhitungan pengujian hipotesis seara parsial memiliki thitung sebesar 3,254 dan nilai ttabel sebesar 1,663 ma ka nilai thitung >ttabel $(3,254>1,663)$ dan nilai sig. $0.00<0,002$. Hal ini berarti hipotesis diterima yaitu: pelatihan berpengaruh positif dan signifikan terhadap produktivitas karyawan $\mathrm{p}$ ada PT Telkom Akses Medan.

Hasil ini sejalan dengan pendapat Hasibuan (2011), dalam Jurnal Ichwan Aziz Sambodo (2016) menyatakan bahwa dengan adanya pelaksanaan program pelatihan dapat membentuk dan meningkatkan kemampuan dan pengetahuan karyawan, sehingga diharapkan dengan semakin sering program pelatihan dilaksanakan maka semakin tinggi pula tingkat produktivitasnya.

Berdasarkan penelitian ini penelitian berpengaruh signifikan terhadap produktivitas kerja karyawan, semakin baik program pelatihan yang diadakan maka akan merangsang karyawan untuk lebih mengasah kemampuan dan skillnya dalam bekerja sehingga karyawan akan memiliki kompetensi yang baik dalam bekerja serta dapat mencapai target dan tujuan perusahaan.

\section{Pengaruh Konseling terhadap Produktivitas}

Hasil perhitungan pengujian hipotesis seara parsial memiliki thitung sebesar 2,974 dan nilai ttabel sebesar 1,663 maka nilai thitung>ttabe $1(2,974>1,663)$ dan nilai sig. $0.00<0,004$. Hal ini berarti hipotesis diterima yaitu : konseling berpengaruh positif dan signifikan terhadap produktivitas karyawan $\mathrm{p}$ ada PT Telkom Akses Medan.

Hal ini sejalan dengan pendapat Dalam jurnal Suwarjo (2012), yang menyatakan bahwa karyawan merupakan salah satu komponen utama dalam perusahaan, maka kualitas dan kesejahteraan karyawan dalam perusahaan sangat menentukan kemajuan dan produktivitas karyawan maupun perusahaan, maka salah satu layanan yang perlu diberikan perusahaan kepada karyawan dalam rangka meningkatkan produktivitas dan kesejahteraan mereka ialah melalui layanan konseling.

Berdasarkan perbandingan hasil perbandingan diatas, maka dapat disimpulkan bahwa pengadaan konseling yang tepat bagi karyawan akan sangat membantu peningkatan produktivitas karyawan, karena pengadaan konseling akan membantu karyawan karyawan yang mengalami stress dalam bekerja sehingga tidak akan menghambat pencapaian target produksi perusahaan.

\section{SIMPULAN}

Dari hasil analisis dan pembahasan dalam penelitian ini, penulis dapat menarik beberapa kesimpulan diataranya: 
1. Hasil pengujian secara parsial dapat disimpulkan bahwa variabel rekrutmen $\left(\mathrm{X}_{1}\right)$ memiliki thitung sebesar 0,837 dan nilai tabel sebesar 1,663 maka nilai $\mathrm{t}_{\text {hitung }}<\mathrm{t}_{\text {tabel }}(0,837<1,663) \quad$ dan nilai

sig.0.00<0,405. Hal ini berarti hipotesis ditolak yaitu : rekrutmen secara parsial tidak berpengaruh positif dan signifikan terhadap $\mathrm{p}$ roduktivitas karyawan pada PT Telkom Akses Medan.

2. Hasil pengujian secara parsial dapat disimpulkan bahwa Variabel pelatihan $\left(\mathrm{X}_{2}\right)$ memiliki thitung sebesar 3,254 dan nilai tabel sebesar 1,663 ma ka nilai $\mathrm{t}_{\text {hitung }}>\mathrm{t}_{\text {tabel }}(3,254>1,663)$ dan nilai sig. $0.00<0,002$. Hal ini berarti hipotesis diterima yaitu : pelatihan berpengaruh positif dan signifikan terhadap produktivitas karyawan $\mathrm{p}$ ada PT Telkom Akses Medan.

3. Hasil pengujian secara parsial dapat disimpulkan bahwa Variabel konseling $\left(\mathrm{X}_{3}\right)$ memiliki thitung sebesar 2,974 dan nilai $t_{\text {tabel }}$ sebesar 1,663 maka nilai $\mathrm{t}_{\text {hitung }}>\mathrm{t}_{\text {tabe }} 1(2,974>1,663)$ dan nilai sig. $0.00<0,004$. Hal ini berarti hipotesis diterima yaitu : konseling berpengaruh positif dan signifikan terhadap produktivitas karyawan pada PT Telkom Akses Medan.

4. Hasil pengujian hipotesis diperoleh nilai $F_{\text {hitung }}$ sebesar 12,932 lebih besar dari $F_{\text {tabel }}$ sebesar 2.72 dengan sig. $0.000<0.000$ maka hal ini menunjukkan bahwa $\mathrm{H}_{0}$ ditolak dan Ha diterima. Dengan demikian rekrutmen $\left(\mathrm{X}_{1}\right)$, pelatihan $\left(\mathrm{X}_{2}\right)$, dan konseling $\left(\mathrm{X}_{3}\right)$ secara simultan (bersama-sama) berpengaruh positif dan signifikan terhadap variable produktivitas (Y).

\section{DAFTAR PUSTAKA}

Edy Sutrisno.2016. Manajemen Sumber Daya Manusia. Edis Pertama. Cetakan ke-8. Jakarta:Kencana. Prenadamedia Group.

Edy Sutrisno. 2017. Budaya Organisasi. Edisi ke4. Jakarta:Kencana. Prenadamedia Group.

Hasibuan, Malayu SP. 2011. Manajemen Sumber Daya Manusia. Jakarta : PT. Bumi Askara.

Ichwan Aziz Sambodo (2016). Pengaruh Pelatihan terhadap Produktivitas Kerja Karyawan Pada PT. Waskita Karya (Persero) Tbk. Cabang. Sulawesi. Skripsi Fakultas Ekonomi dan Bisnis. Universitas UIN Alauddin. Makassar.

Kasmir. (2018). Manajemen Sumber Daya Manusia (Teori dan Praktik). Depok : PT. Rajagrafindo Persada

Nursyaidah Fitriani. (2018). Pengaruh Rekrutmen dan Pelatihan terhadap Produktivitas Kerja Karyawan, Suatu studi pada Toserba Padjajaran Kota Banjar. Jurnal Ekonomi Bisinis.

S.T.N.Din.,J.S.B.Sumarauw., $2018 . \quad$ Pengaruh Rekrutmen, Seleksi, dan Penempatan Kerja terhadap Produktivitas Kerja di PT.HM.Sampoerna.Tbk The Effect Of
Recruitment, Selection, And Work Placement On Work. Jurnal EMBA: Jurnal Riset Ekonomi, Manajemen, Bisnis dan Akuntansi, 6(4). https://doi.org/10.35794/emba.v6i4.21929

Sugiyono. (2017). Metode Penelitian Kuantitatif, Kualitatif, dan R\&D. Bandung: Alfabeta, CV.

Suwarjo (2012).Pengembangan SDM Melalui Konseling di Dunia Industri da Tantangan Globalisasi.

Wibowo.2011. Manajemen Kinerja. Edisi 5.. Jakarta: PT Raja Grafindo Persada. 